\title{
Escolhas Estratégicas e Estilo Cognitivo: um Estudo com Pequenas Empresas
}

\author{
Fernando Antonio Prado Gimenez
}

\section{RESUMO}

Este estudo objetivou descrever as estruturas cognitivas adotadas por dirigentes de pequenas empresas na administração estratégica de seus negócios. A influência dos estilos cognitivos dos dirigentes sobre suas decisões estratégicas foi analisada, bem como o papel da turbulência ambiental na escolha de estratégias. Uma análise cuidadosa dos modelos de Miles e Snow (1978) e Kirton (1976) sugeriu que a estratégia prospectora pode ser preferida por indivíduos cujas características psicológicas indiquem uma preferência por inovação. Por outro lado, a estratégia defensiva parece ser mais atraente a indivíduos que prefiram um estilo adaptativo de solução de problemas. $\mathrm{O}$ método de pesquisa envolveu um conjunto de dezenove entrevistas com dirigentes de pequenas empresas em dois tipos de ambientes: um altamente competitivo e dinâmico, em termos de tecnologia, e outro um pouco menos turbulento. Uma amostra adicional de 14 empreendedores permitiu explorar com mais detalhes a relação entre estilos cognitivos, turbulência ambiental e escolhas estratégicas. Os resultados indicaram que há boas razões para acreditar que diferenças ambientais foram associadas a diferentes escolhas estratégicas, enquanto preferências cognitivas não parecem estar fortemente associadas a formação da estratégia.

Palavras-chaves: estratégia; estilo cognitivo; estrutura cognitiva; pequena empresa.

\begin{abstract}
This study describes the cognitive structure adopted by small firms' owners and managers in the strategic management of their businesses. The influence of respondents' cognitive styles over strategic decisions was explored, as well as the role exerted by environmental turbulence on strategic choices. A careful exploration of Miles and Snow's (1978) taxonomy of strategic types and Kirton's (1976) Adaptation-Innovation theory suggested that a prospector strategy may be preferred by individuals whose psychological characteristics indicate an innovative behaviour. On the other hand, defensive strategies seem to be most attractive to individuals who prefer an adaptive cognitive style. The research method involved a set of nineteen interviews with small firms' owner-managers in two types of environemt: one highly dynamic and competitive in terms of techonlogy, and another less turbulent. An additional sample of fourteen entrepreneurs allowed a more detailed exploration of the association between environmental turbulence, cognitive style, and strategic choices. Results indicated that there are good reasons to believe that environmental turbulence is associated with strategic choices, while cognitive preferences do not seem to be associated with strategy formation.
\end{abstract}

Key words: strategy; cognitive style; cognitive structure; small firms. 


\section{INTRODUÇÃO}

Os estudos relacionados à administração estratégica de grandes e pequenas empresas têm, em geral, adotado um de dois paradigmas predominantes na área: (1) abordagens contingenciais que explicam a relação entre estrutura organizacional e estratégia, ou entre ambiente e estratégia, que definem o chamado paradigma da escolha estratégica (Child, 1972); e (2) estudos sob a égide do determinismo ambiental, que minimiza o papel do administrador estratégico e tem sido chamado de paradigma da ecologia organizacional (Freeman e Boeker, 1984).

Os dois tipos de abordagem não dão relevância ao papel que características pessoais dos administradores exercem nas organizações; no entanto Kets de Vries e Miller (1984) afirmam que atributos organizacionais refletem as personalidades dos administradores mais influentes em qualquer organização. Por outro lado, Hambrick e Mason (1984, p. 193) comentam que "os resultados organizacionais - estratégias e efetividade - são vistos como reflexos das bases cognitivas de atores poderosos na organização".

Desta maneira pareceu importante explorar escolhas estratégicas através da avaliação do papel exercido pelas características pessoais de tomadores de decisão em empresas. A justificativa para este tipo de estudo é particularmente forte no caso de pequenas empresas, nas quais o empreendedor é o principal ator, às vezes o único, do comportamento estratégico da empresa.

Apesar do grande número de estudos relacionados à administração estratégica em pequenas empresas (e. g.: Robinson Jr. e Pearce II, 1984; D’Amboise, 1991; Gimenez, 1996 ), parece que as razões que levam a determinadas escolhas estratégicas, feitas por empreendedores neste tipo de empresa, ainda não são claramente entendidas. Assim como na pesquisa em administração estratégica de grandes empresas, o que está faltando na área é atenção com a cognição administrativa (Stubbart, 1989).

Nesta linha, um aspecto que não tem sido explorado na literatura relacionada com administração estratégica de pequenas empresas é o potencial impacto do estilo cognitivo de seus dirigentes. Estilo cognitivo tem sido definido como diferenças individuais estáveis na preferência por modos de obter, de organizar e utilizar a informação na tomada de decisões (Kirton, 1976).

A escolha de uma direção estratégica qualquer pode ser associada à avaliação que dirigentes fazem de seu ambiente competitivo. De fato, a maior parte da lite- 
ratura sobre estratégia indica a necessidade de avaliar o ambiente competitivo como passo importante no processo de formulação estratégica (Porter, 1979a; Ansoff, 1987; Johson e Scholes, 1989). A avaliação do ambiente competitivo em uma pequena empresa é processo de busca e organização de informações ambientais em uma estrutura coerente que auxilie a tomada de decisão. Assim, pode ser que esta avaliação seja influenciada pelo estilo cognitivo individual e, indiretamente, possa afetar decisões estratégicas.

\section{Que é estratégia?}

Dentro da volumosa literatura sobre estratégia não há nenhuma definição universalmente aceita do que seja estratégia. O termo é usado muitas vezes sem as necessárias clarificações, o que dificulta o desenvolvimento de abordagens integrativas no estudo de estratégia organizacional (Ginsberg, 1984).

Mintzberg (1973, 1978, 1987, 1994) desenvolveu uma série de estudos nos quais ele procura dar um pouco de estrutura ao campo. Muito do que tem sido escrito sobre estratégia pressupõe sua conceituação como conjunto de diretrizes conscientemente deliberadas que orientam as decisões organizacionais. Este conceito chamado de estratégia intencionada por Mintzberg (1978) é representativo das escolas prescritivas de pensamento estratégico. No entanto Mintzberg (1978) chama também a atenção para o fenômeno das estratégias realizada e emergente, ou seja, muitas vezes as estratégias surgem como padrões percebidos em decisões passadas e só então passam a ter caráter de plano para o futuro.

Em Mintzberg (1987) pode-se encontrar pelo menos quatro conceituações diferentes para estratégia:

- Um curso de ação conscientemente definido para a organização.

- Um padrão percebido em um conjunto de ações, fruto de decisões empresariais e gerenciais.

- Uma busca de posição competitiva no mercado.

- Uma visão ou perspectiva que surge através do lider principal da organização.

A busca por taxonomias de estratégias genéricas é característica de boa parte da literatura sobre administração estratégica (Herbert e Deresky, 1987; Miller e Dess, 1993).

A taxonomia proposta por Miles e Snow (1978) tem tido ampla aceitação pelos 
pesquisadores na área de administração estratégica (Segev, 1987; Shortel e Zajac, 1990; James e Hatten, 1995), especialmente entre os estudiosos da área em pequenas empresas (Davig, 1986; Rugman e Verbeke, 1987; Olson e Currie, 1992). Miles e Snow (1978) propõem a existência de quatro tipos de estratégias genéricas: defensiva, prospectora, analítica e reativa. Esses autores propuseram categorias de estratégia competitiva que diferenciam as empresas através da relação estratégia/estrutura e ambiente. Estas se diferenciam nas respostas que as empresas dão aos três problemas que compõem o ciclo adaptativo: (a) problema empreendedor: definição do domínio de produto/mercado; (b) problema de engenharia: escolha de sistemas técnicos; e (c) problema administrativo: relacionado à estrutura e processos organizacionais.

As duas categorias mais contrastantes são: (1) estratégia prospectora, caracterizada por elevada busca de mercados e inovação de produtos e processos; e (2) estratégia defensiva, caracterizada por estreitos domínios de produtos/mercados, e ênfase muito grande em eficiência. A terceira categoria - analítica - pode ser vista como híbrido de estratégia prospectora e defensiva, possuindo área central de negócios mais estável, e componente de negócios mais dinâmico, tratado de forma prospectora. Finalmente, há empresas que parecem não apresentar nenhuma relação coerente entre estratégia e estrutura, e têm uma não-estratégia de reações impulsivas a eventos do ambiente. O Quadro 1 sintetiza as características de cada categoria estratégica.

\section{Quadro 1: Categorias Estratégicas de Milles e Snow (1978)}

\begin{tabular}{|c|l|}
\hline $\begin{array}{c}\text { Categoria } \\
\text { estratégica }\end{array}$ & \multicolumn{1}{|c|}{ Descrição } \\
\hline $\begin{array}{c}\text { Estratégia } \\
\text { defensiva }\end{array}$ & $\begin{array}{l}\text { Uma empresa seguindo esta estratégia procura localizar e manter uma linha de } \\
\text { produtos/serviços relativamente estável. Seu foco concentra-se em uma gama de } \\
\text { produtos/serviços mais limitada do que seus concorrentes e tenta proteger seu domínio } \\
\text { através da oferta de produtos com melhor qualidade, serviços superiores e/ou menores } \\
\text { preços. Não procura estar entre os líderes da indústria, restringindo-se àquilo que sabe fazer } \\
\text { tão bem ou melhor que qualquer um }\end{array}$ \\
\hline $\begin{array}{c}\text { Estratégia } \\
\text { prospectora }\end{array}$ & $\begin{array}{l}\text { Uma empresa que adota esta estratégia está continuamente ampliando sua linha de } \\
\text { produtos/serviços. Enfatiza a importância de oferecer novos produtos/serviços em uma área } \\
\text { de mercado relativamente mais ampla. Valoriza ser uma das primeiras a oferecer novos } \\
\text { produtos, mesmo que todos os esforços não se mostrem altamente lucrativos }\end{array}$ \\
\hline $\begin{array}{c}\text { Estratégia } \\
\text { analítica }\end{array}$ & $\begin{array}{l}\text { Uma empresa que segue esta estratégia tenta manter uma linha limitada de } \\
\text { produtos/serviços relativamente estável e ao mesmo tempo tenta adicionar um ou mais } \\
\text { novos produtos/serviços que foram bem sucedidos em outras empresas do setor. Em muitos } \\
\text { aspectos é uma posição intermediária entre as estratégias defensiva e prospectora }\end{array}$ \\
\hline Estratégia & $\begin{array}{l}\text { A firma que adota uma estratégia reativa exibe um comportamento mais inconsistente do } \\
\text { que os outros tipos. É uma espécie de não-estratégia. Não arrisca em novos } \\
\text { produtos/serviços a não ser quando ameaçada por competidores. A abordagem típica é } \\
\text { esperar para ver e responder somente quando forçada por pressões competitivas para } \\
\text { evitar a perda de clientes importantes e/ou manter lucratividade }\end{array}$ \\
\hline
\end{tabular}


O estudo descrito neste trabalho adotou o conceito de estratégia como posição competitiva em um mercado e buscou identificar as escolhas estratégicas dos respondentes conforme o modelo proposto por Miles e Snow (1978).

\section{Estilo Cognitivo}

A cognição está relacionada à forma como as pessoas adquirem, armazenam e usam conhecimento (Hayes e Allinson, 1994). Por volta de meados da década de 1950, os pesquisadores começaram a se interessar por diferenças no processamento de informações (estilo cognitivo) em oposição a estudos de habilidade cognitiva (nível cognitivo). Enquanto diferentes níveis de habilidades cognitivas podem levar a diferentes níveis de desempenho, estilos não têm relação com eficácia ou eficiência e podem ser julgados mais ou menos adequados a determinadas situações.

Hayes e Allinson (1994) discutem a importância de analisar os fenômenos organizacionais sob o ponto de vista de estilos cognitivos e listam 22 dimensões diferentes pelas quais o estilo cognitivo pode ser observado. Entre estas dimensões destaca-se o modelo proposto por Kirton (1976), isto é, a Teoria da Adaptação-Inovação.

Kirton (1976) propôs que os indivíduos adotam estilos preferidos de criatividade, solução de problemas e tomada de decisão. Esta teoria define um continuum com dois pólos distintos de tomada de decisão e solução de problemas, indicando uma preferência por fazer as coisas melhor ou fazer as coisas diferentemente. Os extremos deste continuum foram denominados preferências de comportamento adaptativo ou inovativo, respectivamente. Indivíduos que têm estilo adaptativo enfatizam precisão, eficiência, disciplina e atenção às normas. Eles tentam resolver problemas através da aplicação de soluções que derivam de métodos conhecidos e já testados. O estilo inovador, por outro lado, é caracterizado como sendo indisciplinado, desafiador de regras, e que procura maneiras novas e diferentes de resolver problemas.

A preferência individual por um estilo cognitivo é medida através de um instrumento desenvolvido por Kirton (1976). Este instrumento já foi amplamente testado e validado (Goldsmith, 1984; Kirton, 1987; Foxall e Hackett, 1992), bem como a teoria de adaptação e inovação tem sido objeto de atenção por crescente número de estudiosos, com mais de 150 publicações entre 1980 e 1990. Essa preferência por um estilo pode ser associada a diversas características de personalidade (Kirton e Ciantis, 1986), o que indica estabilidade ao longo do tempo no comportamento adaptativo ou inovativo. 


\section{MetOdologia do ESTUdo}

Este estudo objetivou descrever as estruturas cognitivas adotadas por dirigentes de pequenas empresas na administração estratégica de seus negócios. A influência dos estilos cognitivos dos dirigentes sobre suas decisões estratégicas foi analisada, bem como o papel da turbulência ambiental e de diferenças de setor na escolha de estratégias. As perguntas de pesquisa a que se buscou responder foram:

- Quais são as características essenciais das estruturas cognitivas usadas pelos dirigentes de pequenas empresas no que diz respeito à concorrência?

- Há alguma associação entre estilo cognitivo e diferenças de estrutura cognitiva?

- Há alguma associação entre diferentes escolhas estratégicas e estilo cognitivo?

- A turbulência ambiental influencia escolhas estratégicas?

- Existe alguma associação entre estilo cognitivo, ambiente competitivo e estratégia?

Uma análise cuidadosa dos modelos de Miles e Snow (1978) e Kirton (1976) sugeriu que a estratégia prospectora pode ser preferida por indivíduos, cujas características psicológicas indiquem preferência por inovação. Por outro lado, a estratégia defensiva parece ser mais atraente a indivíduos que prefiram o estilo adaptativo de solução de problemas.

O método de pesquisa envolveu um conjunto de 19 entrevistas com dirigentes de pequenas empresas em dois tipos de ambientes: um altamente competitivo e dinâmico em termos de tecnologia, e outro um pouco menos turbulento. Os ambiente foram escolhidos tendo como pressuposto a idéia de que o componente tecnológico leva a maior nível de dinamismo ou turbulência ambiental, quando os mercados estão engajados em processos/produtos mais sofisticados e recentes em termos tecnológicos (Chaganti, 1987; Covin e Slevin, 1989; Gronhaug e Falkenberg, 1989). Tal diferenciação permitiu explorar diferenças em termos de estratégia e cognição em diferentes ambientes. Uma amostra adicional de 14 empreendedores permitiu explorar com mais detalhes a relação entre estilos cognitivos, turbulência ambiental e escolhas estratégicas.

Os dados foram coletados, no caso da $1^{\mathrm{a}}$ amostra, através de entrevistas estruturadas utilizando-se da técnica de grades de repertório (Repertory Grid) para elicitação dos construtos usados pelos respondentes para descrever seus ambientes competitivos. Essa técnica deriva da Psicologia dos Construtos Pessoais (Kelly, 1991) e é usada como técnica não intrusiva de tentar entender o mundo como as pessoas o veem, com o mínimo de interferência do pesquisador (Fransella e Bannister, 1977). Os respondentes preencheram o instrumento que mede suas preferências por estilo cognitivo segundo Kirton (1976) e responderam a um ques- 
tionário com informações sobre suas empresas e sobre a estratégia adotada nos termos de Miles e Snow (1978).

A $2^{\mathrm{a}}$ amostra forneceu os mesmos tipos de dados, com exceção da entrevista. Para identificar a visão que os respondentes tinham de seus respectivos ambientes competitivos foi utilizado um formulário montado com os 10 construtos mais utilizados pelos entrevistados na $1^{\mathrm{a}}$ amostra.

\section{Resultados}

Os resultados descritos e analisados nesta seção correspondem aos dados coletados com 19 dirigentes de pequenas empresas situadas no noroeste da Inglaterra. As empresas possuíam em média 46 empregados $(\min =0$, máx $=200)$, com uma idade média de 25 anos, variando de 2 a 125 anos. Seus dirigentes estavam no comando das respectivas empresas, em média, por quase 10 anos, e seu tempo médio de experiência nos respectivos setores era de 18 anos. O resultado médio na escala de adaptação-inovação para este grupo ficou no lado inovador $($ média $=109,1)$. A maioria das empresas estava crescendo. A média de crescimento no faturamento das empresas, nos últimos 3 anos, foi de $16 \%$ ao ano. A Tabela 1 apresenta os dados dos dois subgrupos de respondentes.

\section{Tabela 1: Características dos Subgrupos de Empresas}

\begin{tabular}{|l|c|}
\hline EMPRESAS DE ALTA TECNOLOGIA & Média \\
\hline Variável & 48.5 \\
\hline Número de empregados & 13.1 \\
\hline Idade da empresa (anos) & 17 \\
\hline Crescimento médio no faturamento - 3 anos - (\%) & 15.3 \\
\hline Experiência no setor (anos) & 7.7 \\
\hline Tempo no cargo (anos) & 110.5 \\
\hline Estilo cognitivo & Média \\
\hline EMPRESAS DE TECNOLOGIA TRADICIONAL & 41.6 \\
\hline Variável & 43.4 \\
\hline Número de empregados & 14 \\
\hline Idade da empresa (anos) & 13.4 \\
\hline Crescimento médio no faturamento - 3 anos - (\%) & 22.1 \\
\hline Experiência no setor (anos) & 106.6 \\
\hline Tempo no cargo (anos) & \\
\hline Estilo cognitivo & \\
\hline
\end{tabular}


O grupo de alta tecnologia era composto por empresas que atuavam no setor de produtos eletrônicos em sua totalidade. O grupo de tecnologia tradicional, por sua vez, contava com cinco empresas do ramo de confecções e duas empresas que tomaram parte em um estudo piloto - uma da área de construção civil e outra da área de metalurgia. As empresas de alta tecnologia são mais novas do que as do grupo tradicional. Esta diferença causou reflexos na experiência dos dirigentes no setor, com uma média de anos mais alta também para o grupo de tecnologia tradicional. Por outro lado, o crescimento médio no faturamento foi mais alto para as empresas de alta tecnologia.

É interessante notar que a média de estilo cognitivo foi mais alta no setor de produtos eletrônicos. Este resultado é compatível com a idéia de que setores mais dinâmicos, com ritmo de inovação tecnológica mais intenso, atraem indivíduos com estilo mais inovador; contudo os dois grupos obtiveram média de estilo cognitivo no lado inovador, confirmando os resultados obtidos em outros estudos com empreendedores.

\section{A Natureza dos Construtos Utilizados pelos Respondentes}

Uma lista de 156 construtos foi gerada através das entrevistas e analisada por três pesquisadores independentes para proceder à sua classificação. A análise primeiro classificou os construtos em duas categorias amplas. (1) holísticos: atributos que descrevem uma empresa como um todo, são atribuíveis à empresa e não a departamentos ou operações específicas; e (2) específicos: atributos que descrevem departamentos e operações da empresa, isto é, não são descrições genéricas da empresa. Em uma segunda etapa, estes foram subdivididos em grupos menores.

Os construtos holísticos foram subdivididos em dois grupos. Um conjunto de construtos que indicavam a força dos concorrentes, seu nível de empreendedorismo, seu desempenho no mercado, graus de diversificação, e descrições genéricas de tipos de empresas compuseram um subgrupo de construtos associados à posição competitiva. O segundo subgrupo, atributos das empresas, foi composto por construtos relacionados à tamanho, imagem, idade e estrutura administrativa, descrevendo o que chamei de características demográficas das empresas. 


\section{Quadro 2: Categorias de Construtos}

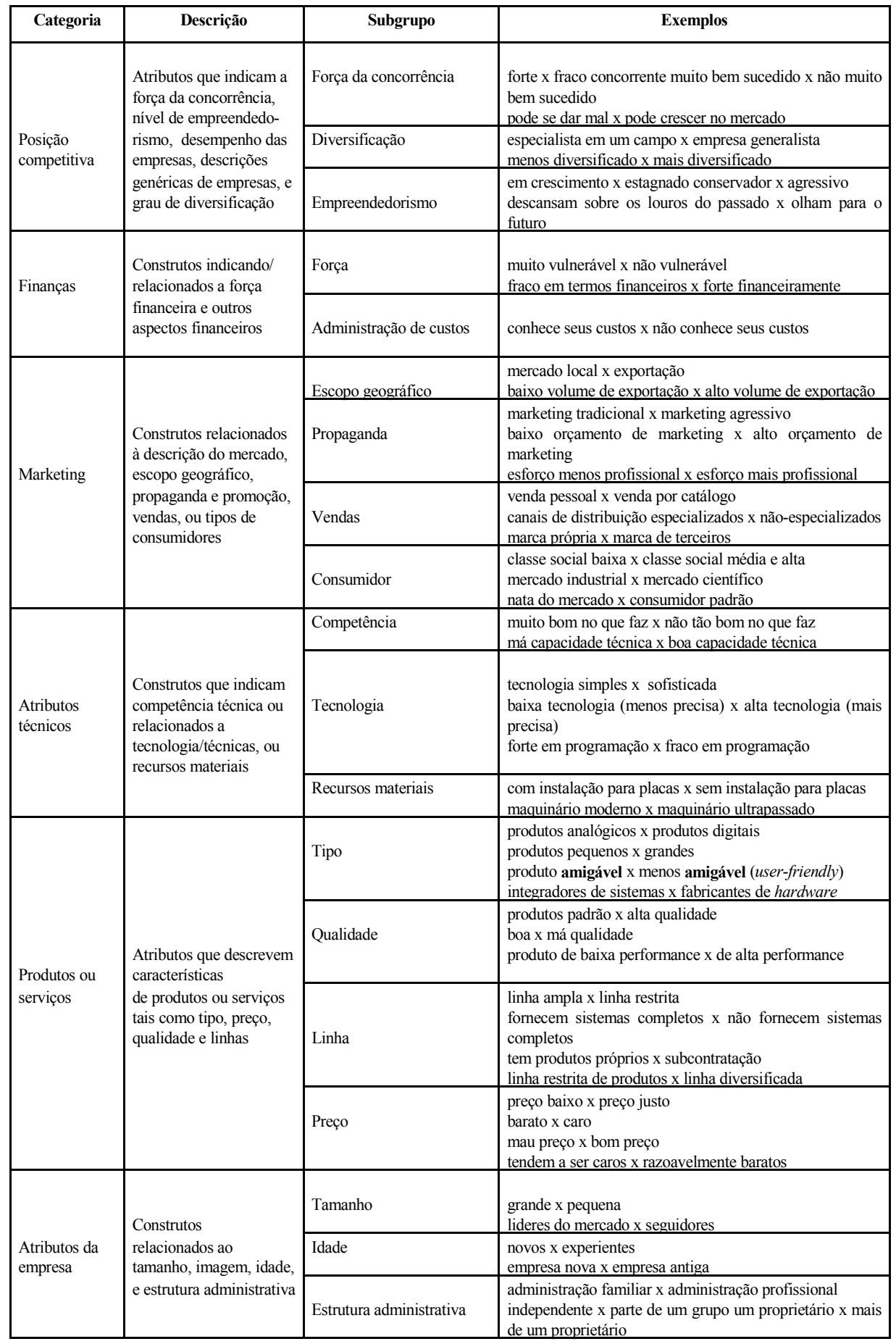


Por outro lado, os construtos específicos foram subdivididos em grupos associados às áreas da administração de uma empresa. Dessa forma, os construtos de marketing descreviam o escopo geográfico, o esforço de propaganda, as vendas e os tipos de consumidores. Construtos ligados a produtos/serviços estavam associados à atributos tais como preço, tipo de produto, qualidade, ou linhas de produtos. Os construtos agrupados em finanças indicavam ou associavam-se à força financeira dos concorrentes e outros aspectos financeiros. Por fim, os atributos técnicos indicavam competência técnica ou se relacionavam a tecnologia/técnicas, ou recursos materiais. O Quadro 2 apresenta alguns exemplos dos construtos elicitados junto aos respondentes.

A maioria dos construtos pertence ao grupo dos específicos $(55,8 \%)$. Entre estes, o subgrupo mais numeroso foi o de construtos relacionados a produtos/ serviços $(31,8 \%)$, com os relativos a marketing representando $12,8 \%$. Os atributos da empresa, no conjunto dos construtos holísticos, foram os mais freqüentes $(30,1 \%)$, e os indicadores de posição competitiva representaram $14,2 \%$. Os construtos relacionados a finanças e atributos técnicos foram os menos freqüentes com $3,8 \%$ e $7,7 \%$, respectivamente, do total de construtos elicitados nas entrevistas.

As dimensões mais freqüentemente utilizadas pelos respondentes entrevistados envolveram questões assim discriminadas: tamanho da empresa, preço, qualidade, linha de produtos, grau de diversificação, imagem, idade da empresa, vulnerabilidade, força no mercado e tecnologia.

O número médio de construtos para as empresas de alta tecnologia foi de 7,9 $(\min =4$ e máx $=11)$, enquanto para a outra amostra de empresas foi mais alto, $8,6(\min =6$ e máx $=14)$. Os dois conjuntos de empresas apresentaram proporções muito similares de construtos holísticos e específicos. A maioria deles foi de construtos específicos $(55,7 \%$ para alta tecnologia, e $55,8 \%$ para o setor tradicional).

Por outro lado, uma análise dos construtos visando à identificar os mais importantes na estrutura mental de cada respondente, conforme Smith (1986), permitiu verificar que os construtos holísticos são a maioria $(56,2 \%)$. A participação dos diversos subgrupos no total de construtos mais importantes também foi alterada. O subgrupo mais freqüente foi o de atributos da empresa (42,1\%), seguido pelo de produtos e serviços $(22,7 \%)$.

A análise por tipo de empresa também evidenciou algumas diferenças. Os respondentes do setor de alta tecnologia apresentaram a categoria de atributos da empresa, especialmente tamanho e estrutura administrativa, com a maior proporção entre os construtos mais importantes, $44,4 \%$. 
O grupo de empresas tradicionais, por outro lado, indicou também a categoria de atributos da empresa como a mais freqüente, $38,2 \%$ dos construtos, mas estes se concentraram em idéias relacionadas a tamanho e imagem.

\section{Adaptaçăo-Inovaçăo e a Natureza dos Construtos}

O processo de classificação dos construtos usados pelos respondentes na compreensão de seus ambientes competitivos levou à definição de algumas proposições que procuraram associar estilo cognitivo e natureza dos construtos.

A primeira dizia respeito à natureza dos construtos usados pelos empreendedores. Pode-se esperar que indivíduos com preferência adaptativa de estilo tenderiam a apresentar maior proporção de construtos específicos em oposição aos holísticos. Isto pode ser associado à maior atenção que adaptadores prestam em detalhes, sua preocupação com precisão e metodização, levando-os a focar aspectos específicos das empresas concorrentes. Essa proposição foi testada com uma medida que consistiu na proporção entre o número de construtos específicos e holísticos usados pelos respondentes. Uma segunda medida buscou a mesma proporção, mas considerando apenas os construtos mais importantes. Os índices de correlação entre os resultados no teste de adaptação-inovação (KAI) e estas duas medidas, contudo, não foram significativos, embora com valores na direção esperada.

Uma segunda análise procurou detectar diferenças na natureza dos construtos mais importantes para os respondentes, agrupados conforme o estilo cognitivo preferido. Esta abordagem indicou pequenas diferenças entre adaptadores e inovadores. Pouco mais da metade dos construtos mais importantes para adaptadores pertenceu ao grupo de atributos das empresas $(53,3 \%)$, enquanto os demais pertenciam às seguintes categorias: produtos/serviços $(20,0 \%)$; marketing $(13,3 \%)$; finanças e posição competitiva ( $6,7 \%$ cada). Inovadores, por sua vez, indicaram dar maior importância aos atributos da empresa $(38,1 \%)$ e produtos/serviços $(23,8 \%)$. Contudo os construtos relacionados à posição competitiva representaram também uma grande proporção $(16,7 \%)$ dos construtos mais importantes de inovadores. Os demais construtos se distribuíram nas categorias: atributos técni$\cos (7,1 \%)$; marketing $(9,5 \%)$ e finanças $(4,8 \%)$.

Diferenciação na estrutura cognitiva é um conceito relacionado ao número de construtos que alguém usa para perceber elementos em um dado. As entrevistaspiloto indicaram que o adaptador mencionou 14 construtos, enquanto o inovador somente 8. Isto não quer dizer que o inovador não seja capaz de produzir mais construtos, mas apenas que um inovador está satisfeito com menos detalhes do que um adaptador. Uma investigação baseada neste conceito tenderia a supor que 
adaptadores apresentariam estruturas cognitivas com mais diferenciação do que inovadores. O índice de correlação entre o número de construtos e o resultado do $\mathrm{KAI}$ indicou um resultado significativo na direção esperada $(-0,43, \operatorname{com} p=0,033)$.

Finalmente, as estruturas de referência usadas pelos respondentes podem revelar diferentes categorias de concorrentes. De novo, a maior atenção por detalhes dos adaptadores pode resultar em maior variedade de grupos de concorrentes. Esta associação, no entanto, não foi demonstrada nesta pequena amostra que gerou um índice de correlação de $-0,27$ com baixíssima significância $(\mathrm{p}<0,10)$.

\section{Estilo Cognitivo, Estratégia e Ambiente}

Como foi descrito anteriormente, as estratégias adotadas pelas empresas dos respondentes foram classificadas nos termos do modelo de Miles e Snow (1978). Esta classificação permitiu explorar a distribuição das diferentes estratégias nos dois tipos de ambiente.

As proporções de estratégias, como se esperava, foram diferentes, dependendo do ambiente empresarial envolvido. No ambiente mais dinâmico de alta tecnologia, a estratégia mais comum foi a prospectora (6 casos), seguida por analítica (4 casos), e 2 casos de estratégia defensiva.

Para o grupo de empresas no setor tradicional, por outro lado, não houve nenhum caso de estratégia prospectora. As estratégias analíticas e defensivas foram as preferidas pelos empresários desse ambiente, com 3 casos, em cada. Em uma das empresas do grupo não foi possível identificar a estratégia seguida pela falta de respostas às questões.

O padrão de escolhas estratégicas não mostrou diferenças significativas, quando os tipos de estratégias foram cruzados com os diferentes estilos cognitivos. Adaptadores e inovadores se distribuíram em proporções muito semelhantes entre as estratégias defensivas, analíticas e prospectoras. Por fim, deve-se registrar que, no conjunto das duas amostras, não foi identificado nenhum caso de estratégia reativa.

\section{Grupos Estratégicos e Posição Competitiva}

A análise dos dados coletados através da grade de repertório permitiu identificar o agrupamento de empresas semelhantes na visão dos respondentes. Em todos os casos, houve a identificação de pelo menos dois grupos diferentes de concorrentes, sendo a média de 3,5 grupos, com um máximo de seis grupos estratégicos.

A análise dos construtos associados a cada um dos grupos de empresas concor- 
rentes identificados pelos respondentes sugere que estes, independentemente de ambiente competitivo e de estilo cognitivo, parecem compartilhar uma estrutura mental muito similar.

Tal estrutura mental é composta por quatro dimensões que derivam da associação de diferentes conjuntos de construtos muito similares. Essas quatro dimensões estão relacionadas ao tamanho da empresa, ao grau de especialização, ao foco no mercado e ao nível de empreendedorismo.

A primeira dimensão é baseada no porte das empresas. Os respondentes parecem ter, na maioria dos casos, dois grupos distintos de concorrentes: um composto pelo que eles caracterizam como grandes empresas, e outro composto pelos pequenos concorrentes. Esta dimensão parece estar associada à fatia de mercado de cada companhia.

A segunda dimensão dessa estrutura se relaciona ao grau de especialização dos concorrentes no ambiente. Dois grupos principais foram identificados. Aquelas companhias com uma ampla linha de produtos e serviços foram consideradas generalistas, enquanto as companhias com linhas mais limitadas foram chamadas de especialistas, atendendo a nichos de mercado.

A terceira dimensão envolve um grupo de construtos relacionados à qualidade e preço dos produtos ou serviços. Dois grupos diferentes de concorrentes parecem ser identificados com o escopo de mercado que pretendem atender. Há um grupo que busca atender a nata do mercado, com alto preço e boa qualidade, e é considerado líder do mercado. Enquanto o segundo grupo visa ao mercado de baixa renda com produtos de qualidade média ou inferior e preços menores.

A quarta dimensão está relacionada ao grau de proatividade dos concorrentes no mercado. Esta dimensão envolve construtos relacionados à força da concorrência, ao dinamismo das empresas, e ao nível de empreendedorismo. Um grupo de empresas parece ser identificado como empresas proativas no mercado. Estas são caracterizadas como concorrentes fortes, empresas dinâmicas que conhecem as necessidades do mercado muito bem, e são em geral bem sucedidas. As firmas menos proativas, ou reativas, são aquelas cujo dinamismo é bem menor. São consideradas, em geral, como concorrentes fracos, com presença marginal no mercado, tentando vender o que têm, sem muito sucesso.

Essas quatro dimensões compartilhadas podem ser vistas como indicadores da percepção de diferentes grupos estratégicos nos ambientes competitivos. Os grupos estratégicos seriam definidos por empresas que seguem estratégias semelhantes na combinação das quatro dimensões das mais diversas maneiras. 


\section{Estudo 2}

Os resultados do estudo 1 pareceram indicar que a turbulência ambiental teria impacto maior do que o estilo cognitivo em escolhas estratégicas feitas por dirigentes de pequenas empresas. A tarefa difícil de comparar diferentes percepções de turbulência manifestadas nos diversos construtos elicitados dos respondentes levou-me a buscar evidência adicional da influência de turbulência percebida sobre a formação de estratégia. Desta forma, um formulário com os construtos mais freqüentemente citados nas entrevista foi desenhado e usado para coletar dados com uma amostra adicional de catorze empresários nos mais diversos setores.

Esta segunda amostra de empresas foi igualmente dividida em dois grupos, um composto por empresas que atuavam no setor de produtos eletrônicos, e outro composto por um mix de empresas em indústrias tradicionais (confecções, metalurgia e produtos de laser).

A maioria dos respondentes era composta de inovadores $(n=10)$, e somente 4 deles ficaram do lado adaptador da escala de KAI. A média do grupo foi de 107,7, variando de 69 a 133. Os respondentes também forneceram dados sobre a estratégia de suas empresas de acordo com o modelo de Miles e Snow (1978).

O cruzamento dos dados indicou que a estratégia prospectora foi mais freqüente nas empresas de produtos eletrônicos, enquanto os outros respondentes indicaram somente estratégias analítica e defensiva. Novamente, no que diz respeito a estilo cognitivo, nenhuma diferença significativa foi encontrada entre adaptadores e inovadores; contudo o tamanho pequeno da amostra não permite fazer nenhuma afirmação mais forte em qualquer direção.

Um indicador da associação entre as posições competitivas atuais e futuras dos respondentes e as de seus concorrentes foi feito através da contagem do número de concorrentes que se localizavam no mesmo grupo de suas posições atuais e futuras. Isto foi possível, porque o formulário desenhado solicitava que os respondentes analisassem também suas empresas em termos dos construtos listados em dois momentos: posição atual e posição desejada em cinco anos. Esta análise indicou que 9 posições atuais estavam próximas de mais da metade dos concorrentes, enquanto 5 casos estavam próximos de menos da metade dos concorrentes. Por outro lado, as posições competitivas pretendidas para o futuro indicaram 12 casos agrupados com a posição de mais da metade dos concorrentes e somente 2 agrupados com menos da metade dos concorrentes.

A percepção dos respondentes e alocação de seus concorrentes em diferentes grupos estratégicos permitem-lhes que escolham uma posição estratégica neste ambiente competitivo. A análise dos dados coletados permitiu identificar dois 
fatores relacionados a este posicionamento. Em primeiro lugar, parece que, independente de estilo e ambiente, a escolha de uma posição estratégica está associada à estratégia modal, ou seja, à mais freqüente, adotada pelos concorrentes mais significativos. Em segundo lugar, a intenção de mudar o posicionamento estratégico no futuro indicou uma diferença significativa entre adaptadores e inovadores. Os resultados indicaram que os inovadores não desejam mudar sua posição competitiva no futuro, enquanto os adaptadores, na quase totalidade, indicaram uma intenção de mudar sua posição no futuro.

\section{Conclusão}

Os resultados destes dois estudos não podem ser associados facilmente a outros estudos da literatura. Estudos acerca da influência da cognição sobre escolhas estratégicas não abordaram a natureza dos construtos e dirigiram seu foco quase que exclusivamente a grandes empresas (Dutton, Fahey e Narayama, 1983; Walsh, 1988; Calori, Johnson e Sarnin, 1994).

A análise dos construtos elicitados pelas entrevistas, independentemente de estilo ou ambiente, indicou que os respondentes usam uma estrutura cognitiva baseada em construtos holísticos e específicos, envolvendo seis categorias principais. A natureza dos construtos principais nesta estrutura é holística. Isto significa que os respondentes enxergam a concorrência através de categorias mais genéricas, ao invés de prestar atenção a detalhes específicos da concorrência.

Uma preferência por estratégias prospectoras foi identificada no ambiente de alta tecnologia, ao passo que os empreendedores do ambiente industrial tradicional preferiram estratégias analíticas e defensivas. $O$ estilo cognitivo não se associou com escolhas estratégicas; no entanto houve uma associação forte entre intenção de mudança na posição estratégica e estilo cognitivo. Adaptadores indicaram tendência a mudar suas posições no futuro, enquanto nenhum inovador indicou esta tendência.

Uma possível explicação para isto pode ser que adaptadores tendem a mudar gradualmente seus negócios em linha com transformações percebidas no ambiente, enquanto inovadores tendem a se fixar em sua posição estratégica, que pode ser diferente da maioria. As mudanças dos inovadores envolvem cruzar diferentes paradigmas, o que no caso de empreendedores pode significar começar um novo negócio, ao invés de mudar a estratégia competitiva do atual.

Grande número de dimensões têm sido usadas na literatura para identificar grupos estratégicos (Pitts e Hopkins, 1986). As quatro dimensões identificadas neste 
estudo são semelhantes a uso de tamanho por Porter (1979b), conjunto de produtos por Newman (1978), e diferenciação de produtos por Oster (1982); no entanto nenhum estudo anterior sugeriu a combinação dessas dimensões conforme foi elicitado das entrevistas neste estudo.

Finalmente os resultados indicaram que há boas razões para acreditar que diferenças ambientais foram associadas à diferentes escolhas estratégicas, enquanto preferências cognitivas não parecem estar fortemente associadas à formação da estratégia; contudo os tamanhos das amostras sugerem cautela na extrapolação destes resultados.

\section{ReferénCias Biblográficas}

ANSOFF, H. I.

The emerging paradigm of strategic behavior. Strategic Management Journal, v. 8, p. 501-515, 1987.

CALORI, R.;

JOHNSON, G.;

SARNIN, P.

CEO's cognitive maps and the scope of the organization. Strategic Management Journal, v. 15 , n. 6 , p. 437-457, 1994.

CHAGANTI, R.

Small business strategies in different industry growth environments. Journal of Small Business Management, v. 25, $\mathrm{n}$. 3, p. 61-68, 1987.

CHILD, J.

Organizational structure, environment and performance : the role of strategic choice. Sociology, v. 5, p. 01-22, 1972.
COVIN, J. G.; SLEVIN, D. P.

Strategic management of small firms in hostile and benign environments. Strategic Management Journal, v. 10, $\mathrm{n}$. 1, p. 75-87, 1989.

D'AMBOISE, G.

Strategic planning in SMEs - a synthesis of research results. In: ICSB 36TH ANNUAL WORLD CONFERENCE (1991 : Viena). Proceedings ... Viena : 1991.

DAVIG, W.

Business strategies in smaller manufacturing firms. Journal of Small Business Management, v. 24, n. 1, p. 38-46, 1986.

DUTTON, J. E.;

FAHEY, L.;

NARAYANAN, V. K.

Toward understanding strategic issue diagnosis. Strategic Management Journal, v. 4, p. 307-323, 1983. 
FOXALL, G. R.;

HACKETT, P. M. W.

The factor structure and construct validity of the Kirton adaptioninnovation inventory. Personality and Individual Differences, v. 13, n. 9, p. 967-975, 1992.

FRANSELLA, F.;

BANNISTER, D.

A manual for repertory grid technique. London : Academic Press, 1977.

FREEMAN, J.;

BOEKER, W.

The ecological analysis of business strategy. California

Management Review, v. 26, n. 3, p. 73-86, 1984.

GIMENEZ, F. A. P.

Patterns of strategic choice of small firm owners and managers. Manchester, 1996. Thesis (PhD) - University of Manchester.

GINSBERG, A.

Operationalizing organizational strategy : toward an integrative framework. Academy of Management Review, v. 9, n. 3, p. 548-557, 1984.

GOLDSMITH, R. E.

Personality characteristics associated with adaptioninnovation. Journal of Psychology, v. 117, p. 159-165, 1984.

GRONHAUG, K.;

FALKENBERG, J. S.

Exploring strategy perceptions in changing environments. Journal of Management Studies, v. 26, n. 4, p.349-359, 1989.
HAMBRICK, D. C.;

MASON, P. A.

Upper echelons : the organization as a reflection of its top managers. Academy of Management Review, v. 9, n. 2, p. 193-206, 1984.

HAYES, J.;

ALLINSON, C. W.

Cognitive style and its relevance for management practice. British Journal of Management, v. 5, n. 1, p. 53-71, 1994.

HERBERT, T. T.;

DERESKY, $\mathrm{H}$.

Generic strategies : an empirical investigation of typology validity and strategy content. Strategic Management Journal, v. 8, p. 135-147, 1987.

JAMES, W. L.;

HATTEN, K. J.

Further evidence on the validity of the self typing paragraph approach : Miles and Snow strategic archetypes in banking. Strategic Management Journal, v. 16, n. 2, p.161-168, 1995.

JOHNSON, G.;

SCHOLES, K.

Exploring corporate strategy. 2 . ed. Englewood Cliffs, NJ : Prentice-Hall, 1989.

KELLY, G. A.

The psychology of personal constructs. London : Routledge, 1991. v. 1.

KETS DE VRIES, M. F.;

MILLER, D.

The neurotic organisation. London : Jossey-Bass, 1984. 
KIRTON, M. J.

Adaptors and innovators : a description and measure. Journal of Applied Psychology, v. 61, n. 5, p. 622-629, 1976.

Adaptors and innovators : cognitive style and personality. In: Frontiers of creativity research - beyonds the basic. Buffalo : Isaksen, 1987.

KIRTON, M. J.;

DE CIANTIS, S. M.

Cognitive style and personality: the Kirton adaption-innovation and Cattell's sixteen personality factors inventories. Personality and Individual Differences, v. 7, n. 2, p. 141-146.

MILES, R. E.;

SNOW, C. C.

Organizational strategy, structure and process. New York : McGraw-Hill, 1978.

MILLER, A.;

DESS, G. G.

Assessing Porter's (1980) model in terms of its generalizability, accuracy and simplicity. Journal of Management Studies, v. 30, n. 4, p. 553-585, 1993.

MINTZBERG, $\mathrm{H}$.

Strategy-making in three modes. California Management Review, v. 26, n. 2 , p. 44-53, 1973.

Patterns in strategy formation. Management Science, v. 24, n. 9, p. 934-948, 1978.

The strategy concept I : five Ps for strategy. California Management Review, p.11-24, Fall 1987.
The rise and fall of strategic planning. Englewood Cliffs, NJ : Prentice-Hall, 1994.

OLSON, S. F.;

CURRIE, H. M.

Female entrepreneurs : personal value systems and business strategies in a male-dominated industry. Journal of Small Business Management, v. 30, $\mathrm{n}$. 1, p. 49-57, 1992.

OSTER, S.

Intraindustry structure and the ease of strategic change. Review of Economics and Statistics, v. 44, n. 3, p. 376-383, 1982.

PITTS, R. A.; HOPKINS, H. D.

Firm diversity : conceptualisation and measurement. Academy of Management Review, v. 7, n. 4, p. 620-629, 1986.

PORTER, M. E.

How competitive forces shape strategy. Harvard Business Review, v. 57, n. 2, p. 137-145, 1979a.

The structure within industries and companies' performance. Review of Economics and Statistics, v. 61, p. 214-219, 1979b.

ROBINSON JR., R. B.;

PEARCE II, J. A.

Research thrusts in small firm strategic planning. Academy of Management Review, v .9, n. 1, p. 128-137, 1984. 
RUGMAN, A. M.;

VERBEKE, A.

Does competitive strategy work for small business? Journal of Small Business and Entrepreneurship, v. 5, n. 3, p. 45-50, 1987.

SEGEV, E.

Strategy, strategy making and performance - an empirical investigation. Management Science, v. 33, n. 2, p. 258-269, 1987.

SHORTELL, S. M.; ZAJAC, E. J.

Perceptual and archival measures of Miles and Snow's strategic types : a comprehensive assessment of reliability and validity. Academy of Management Journal, v. 33, n. 4, p. 817-832, 1990.

SMITH, M.

An introduction to repertory grids - part one. Graduate Management Review, v. 3, n. 1, p. 04-17, 1986.

STUBBART, C. I.

Managerial cognition : a missing link in strategic management research. Journal of Management Studies, v. 26, n. 4, p. 325-347, 1989.

WALSH, J. P.

The role of cognition in strategy making : an empirical investigation. International Journal of Management, v. 5, n. 2, p. 188-200, 1988. 